\title{
ARTICLE
}

\section{Forest fire risk assessment model using Remote sensing and GIS techniques in Tujiin nars national park, Mongolia}

Munkh-Erdene Altangerel*, Amarsaikhan Damdinsuren Jargaldalai Enkhtuya and Nyamjargal Erdenebaatar

Division of Remote Sensing and Spatial Modeling, Institute of Geography and Geoecology, Mongolian Academy of Sciences, Ulaanbaatar, Mongolia.

\begin{abstract}
Forest is an important natural resource that should be carefully protected and rationally managed. In recent years, deforestation and forest land degradation have become the main concern for forest specialists as well as policy and decision-makers dealing with environment issues. It has been found that much of the existing forests have been destroyed, mainly by shifting cultivation, timber preparation, legal and illegal logging, and forest fires. To protect and conserve the deteriorating forest, it is very important to conduct forest-related risk assessment and map the outcomes in a spatial domain. The aim of this research is to conduct a forest fire risk assessment mapping of Tujiin Nars National Park using geographic information system (GIS) and remote sensing (RS) techniques. The research approach is based on an empirical model. It includes three parameters (i.e. geomorphology, vegetation cover combustibility and human activity) that are crucial for the forest fire assessment. The results of the study can be used for different decision making processes.
\end{abstract}

Keywords: Forest Fire Risk, GIS; RS; Tujiin Nars;

\section{INTRODUCTION}

Forests are an important natural resource that should be carefully managed, because, on one hand, they maintain ecological balance, and on the other hand, they provide the raw material for a wide range of wood-based industries [1]. Forests cover approximately 30 per cent of the land area of the planet, however, estimates suggest that deforestation is occurring at a high rate, predominantly because of human-induced landuse changes. Over 45 per cent of the Earth's original forests have been cleared during the past century. These human induced changes in forest extent and condition impact biodiversity, climate, biochemical cycles and economic development [2].

\footnotetext{
*corresponding author: munkherdenea@mas.ac.mn
}

https://orcid.org/0000-0003-4609-7242

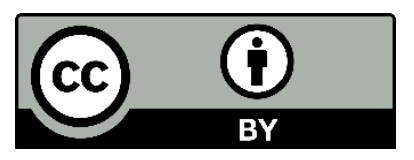

The Author(s). 2021 Open access This article is distributed under the terms of the Creative Commons Attribution 4.0 International License (https://creativecommons.org/licenses/by/4.0/), which permits unrestricted use, distribution, and reproduction in any medium, provided you give appropriate credit to the original author(s) and the source, provide a link to the Creative Commons license, and indicate if changes were made. 
In recent years, deforestation and forest land degradation have become the main concern for forest specialists and ecologists as well as policy and decision-makers dealing with the environment. It has been found that much of the existing forests have been destroyed, mainly by shifting cultivation, timber preparation, legal and illegal logging, forest fires and increased number of people involved in agricultural activities. It is crucially important to conduct thorough planning and management [3] in order to protect and conserve the deteriorating forest.

Incidences of forest fires have been increasing in the past decades. Every year, thousands of hectares of forests are damaged globally. Forests and grasslands play an important role for the economic development of many developing countries. In Mongolia, wild fire is one of the main factors influencing the spatial dynamics of forest ecosystems. For example, in 2019, 121 forest and steppe fires were recorded and 311,798 hectares of forest areas were burnt to ashes. Ecological loss was estimated at 23.7 billion MNT [4].

The main objective of this study is to conduct a fire-risk mapping using GIS and RS methods. The methodology of the study was an empirical model, which integrates parameters grouped into three sub-indexes (i.e. the combustibility index (CI), the topomorphology index (MI) and the human occupation index (HI)).

As a test site, Tujiin Nars National Park located in Selenge aimag, northern Mongolia was selected. The area is one of the historical sites of the country, but highly affected by different forest fires. Recent statistics revealed that approximately 25 wildfires occur every year in areas at and neighbouring with Tujiin Nars.

The results of the study can be used for forest fire prevention and also for supporting other forest-related decision making processes.

\section{Study area and data sources}

The study site is located in Tujiin Nars area, Altanbulag soum, Selenge aimag in the transitional zone where the mountainous zone around Lake Baikal changes to the Northern Mongolian highlands and are part of the northern mountain range. Figure 1 shows location of the study area.

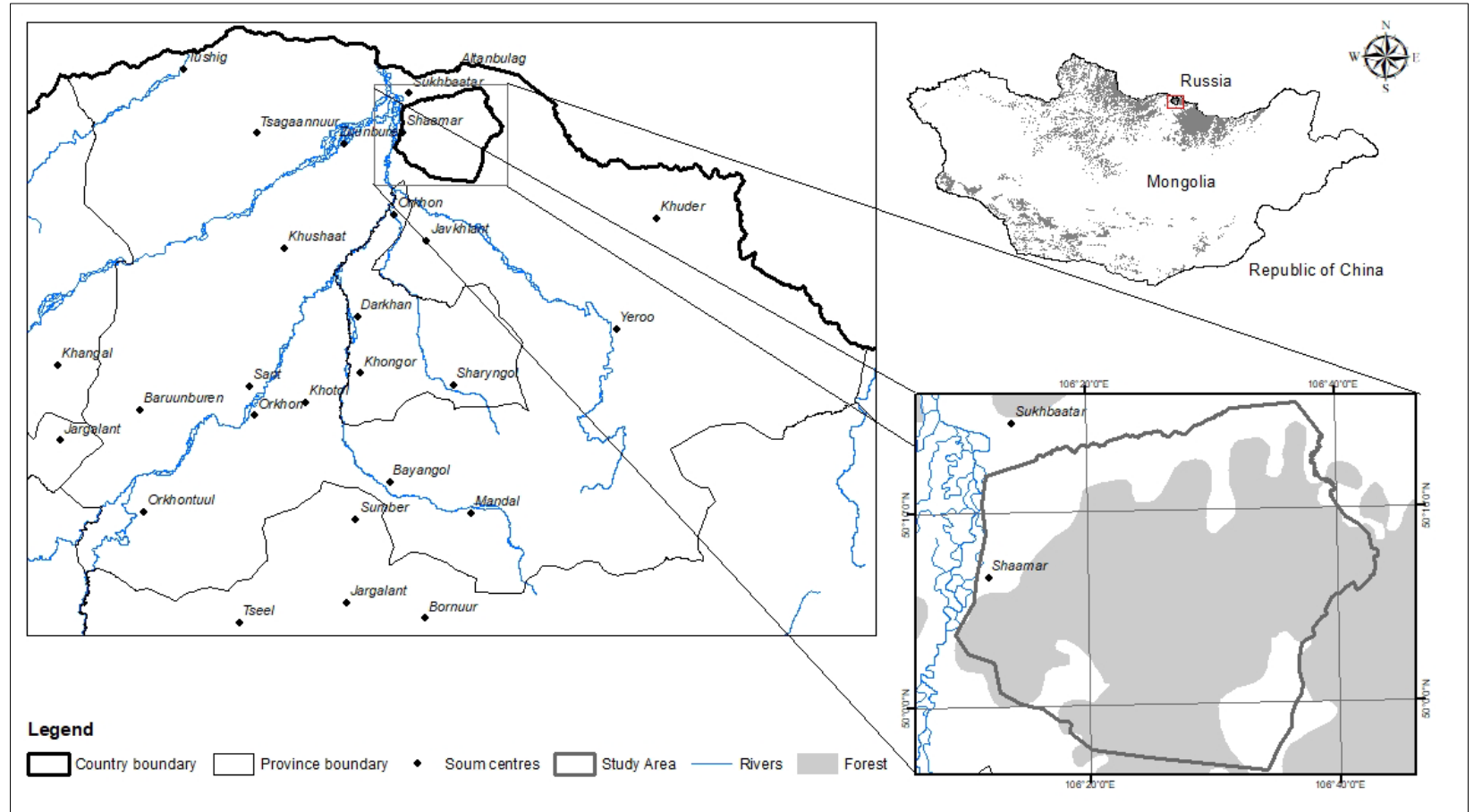

Figure 1. Map of study area

Tujiin Nars National Park covers 45 thousand hectares of area, with Scots pine as the dominant forest species. The area is situated in a high fire-risk zone, where fires mostly occur in spring and autumn. 
According to statistics, more than 19,000 hectares of these degraded forests were restored between 1971 and 2011 [5]. Reforestation activities in Mongolia started in the 1970's. Since then, 98,000 ha have been reforested and restored, 50 per cent were replanted with seedlings [6].

Satellite data used in the current study consisted of a Sentinel 2A optical image acquired in May 2018 and a Sentinel 1B C-band radar data of August 2018. Sentinel-1 is the first of the Copernicus Program satellite constellation conducted by the European Space Agency. This space mission is composed of two satellites, Sentinel-1A and Sentinel-1B that carry a C-band radar instrument. Based on a well-established heritage from the ERS, Envisat and Radarsat missions, Sentinel-1 carries a $12 \mathrm{~m}$ long advanced SAR, working in C-band [7]. Sentinel-2A carries an innovative wide-swath, high resolution, multispectral imager (MSI) with 13 spectral bands [8].

Digital elevation model (DEM) of the study area was derived from Sentinel 1B Cband radar data sets. DEM can be derived from Sentinel 1B data sets by interferometric processing. The procedure to generate a DEM includes the stages and is performed by SNAP software developed by ESA. The spatial resolution of DEM is $10 \mathrm{~m}$. In addition, spatial layers in GIS database have been used. Figure 2 shows satellite data sets of the study area.

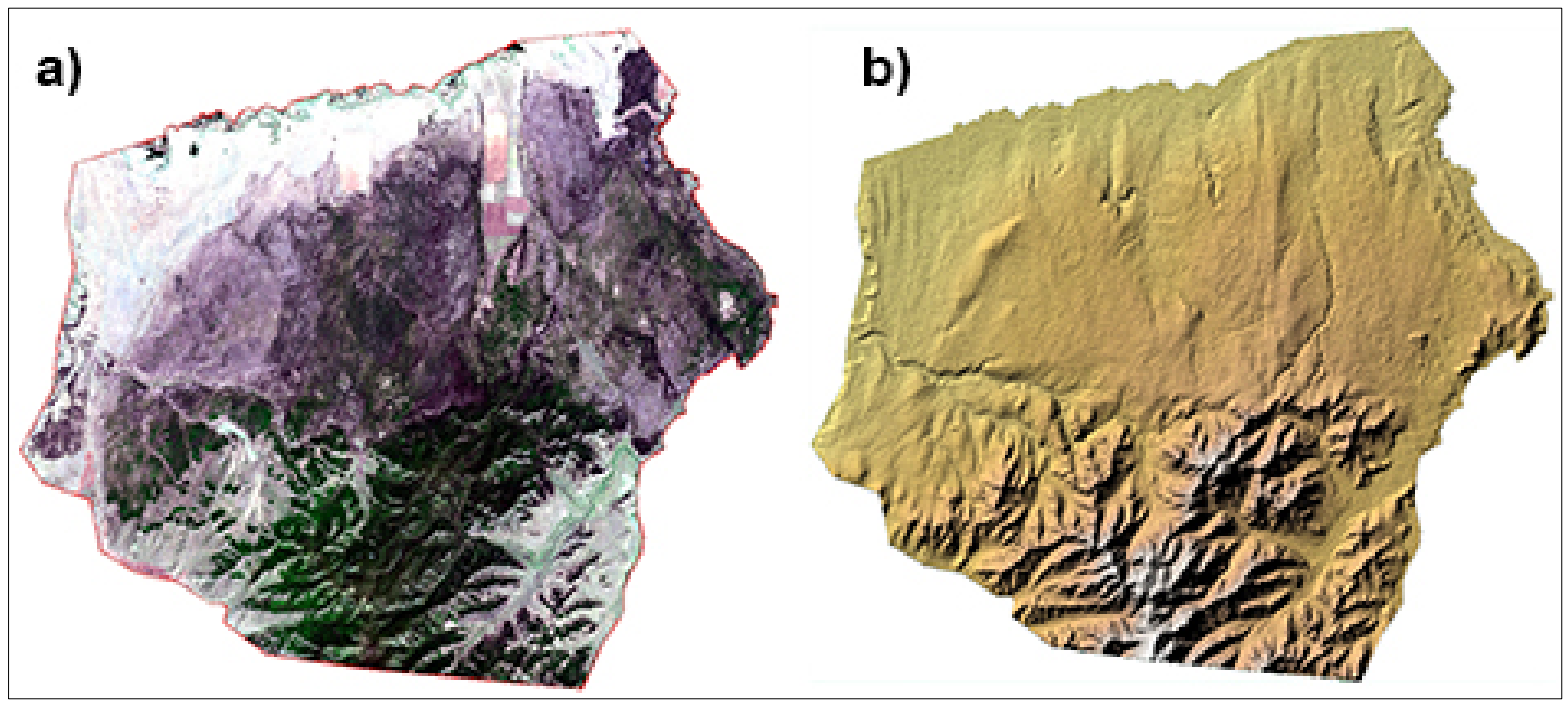

Figure 2. a) Sentinel $2 A$ image, natural color

b) $\operatorname{DEM}(10 \mathrm{~m})$

\section{MATERIALS AND METHODS}

The methodology was based on an empirical model which integrates parameters grouped into three sub-indexes, such as the combustibility index (CI), the topomorphology index (MI) and the human occupation index (HI) [16].

The index is formulated by the following formula:

$$
R I=5 C I+2 M I+3 H I
$$

Where:
RI: Risk index,
CI: Combustibility index;
MI: Topomorphology index;
HI: Land-use index.

\section{The Combustibility Index (CI)}

The Combustibility Index

characterizes the fire and combustion behaviour of a material.

The land use/cover in the study area contains agriculture, forest, water, grassland, and residential area. The land use emphasizes the impact of highly flammable litter, which is the origin of many fires. When fire begins in the litter, it is often difficult to detect. Fire consumes the litter slowly before spreading to the herbaceous layer, which is highly inflammable. Wind can also spread fire over 
large areas, thereby increasing the overall fire risk [9].

The forest stand characteristics, such as structure, existence of vertical or horizontal discontinuities, vegetation cover density, and species composition may have an effect on a forest stand's sensitivity to fire. The intensity, frequency, and size of forest fires are related to the physical (climatic factors) and vegetal environment. The creation and spread of fires are dependent on the combination of different natural conditions and human activity [10].

In this study, the combustibility index (CI) map was extracted from the vegetation map and the NDVI map. Vegetation map is created from Sentinel 2A optical satellite images using an unsupervised classification method and NDVI map is calculated from the same satellite data.

Isodata unsupervised classification method has been selected. Isodata calculates class means evenly distributed in the data space, then iteratively clusters the remaining pixels using minimum distance techniques [17]. Each iteration recalculates means and reclassifies pixels with respect to the new means [17]. Iterative class splitting, merging, and deleting is done based on input threshold parameters. All pixels are classified to the nearest class unless a standard deviation or distance threshold is specified, in which case, some pixels may be unclassified if they do not meet the selected criteria [17]. This process continues until the number of pixels in each class changes by less than the selected pixel change threshold or the maximum number of iterations is reached [17].

\section{The Topomorphology Index (MI)}

The Topomorphology Index (MI) contains three morphological parameters including elevation, slope and aspect datasets. MI is expressed by the following equation:

Where:

$$
M I=3 s+(m * a)
$$

$s-i$ the slope (coded 1 to 4$)$

$m$-is the morphology of the area

\section{$a$-is the aspect (coded 1 to 4}

Slope (s)

Slope is a parameter that influences the fire spread rate [11]. Fire moves more quickly up a slope and less quickly down a slope [12]. Also, the fire spread rate may rise on steeper slopes due to flames being angled closer to the ground surface, and the process of heat convection can be enhanced by wind effects due to fire behaviour [12].

\section{Aspect (a)}

Aspect is correlated with the amount of solar energy and the surrounding area receiving radiation. Vegetation is typically drier and less dense on south-facing slopes than on the north facing ones [14]. Drier fuels are more exposed to ignition risk. In addition, easterly aspects get more ultraviolet and direct sunlight earlier in the day than westerly aspects do. Consequently, easterly aspects become drier faster [14].

\section{Morphological topography (m)}

Topography plays an important and leading role in the behaviour of forest fires by influencing the morphology and speed of fire spread. In general, topographic influences vary depending on slope inclination, exposure, and elevation of the soil [9]. Unlike atmospheric agents, topography is a constant factor from which it is possible to determine and especially predict the influence of fire spread [9].

\section{Human Occupation Index (HI)}

The HI is compiled according to the formula adopted in the two indices, neighbourhoods, and human occupations. It is assimilated by buffer surfaces of $100 \mathrm{~m}$, and by other roads and roadways according to the degree of traffic, and around homes located within or on the edge of the forest. The human occupation index reflects small areas where the risk of forest fires begins; this situation is due to the low human densities and the low density of the road network implanted in the forest [9].

\section{RESULTS AND DISCUSSION}

In this study, the combustibility index (CI) map was extracted from the vegetation 
map (Figure 3) and the NDVI map (Figure 4). Vegetation map is created from Sentinel 2A optical satellite images using Isodata unsupervised classification method as well as NDVI map is calculated from the same satellite data (Figures 3 and 4). The classification result has been compared to land cover created map of the study area in 2014 using Landsat images and forest inventory data of 2008 [18], visually. It showed good results. The research area contains the vegetation cover that includes deciduous, coniferous and mixed forests as well as grassland. Vegetation density, or relative biomass, is considered a significant factor in the spread of forest fires [9]. The generated CI index map is shown in Figure 5.

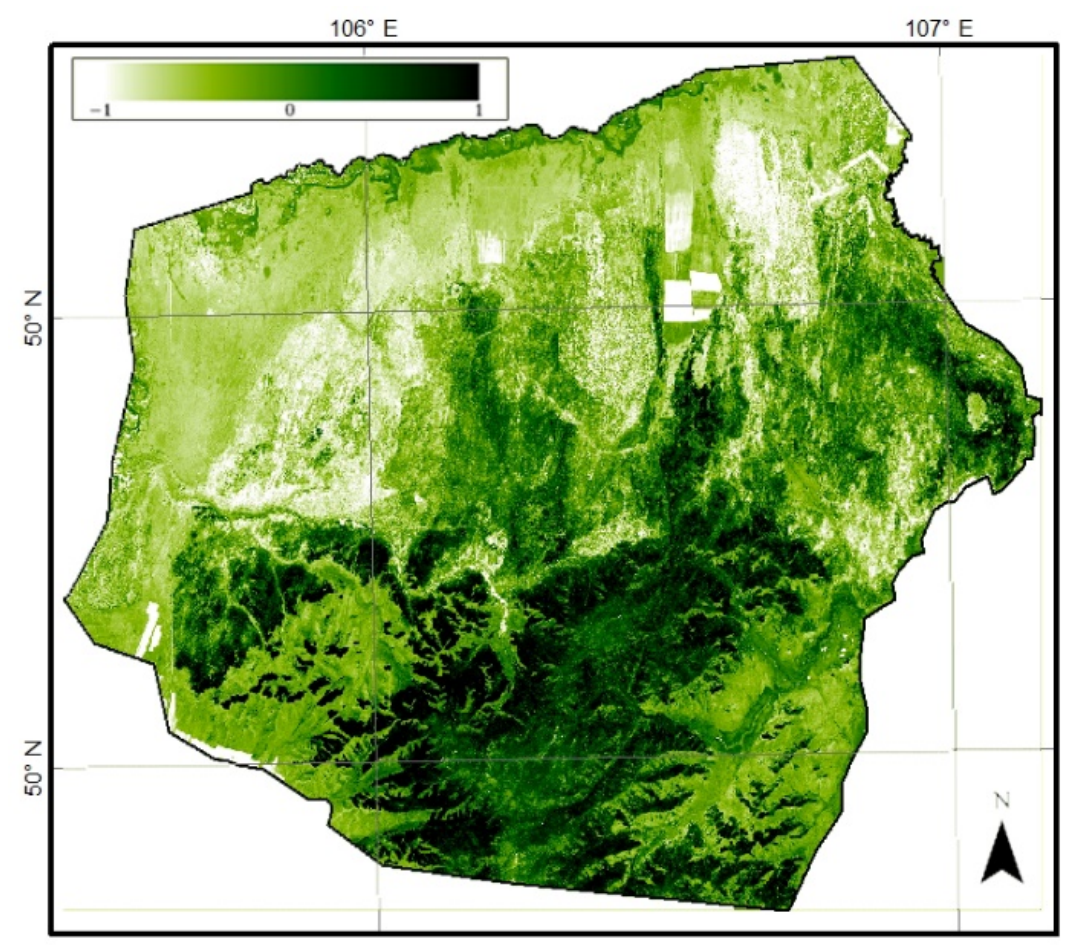

Figure 3. NDVI map

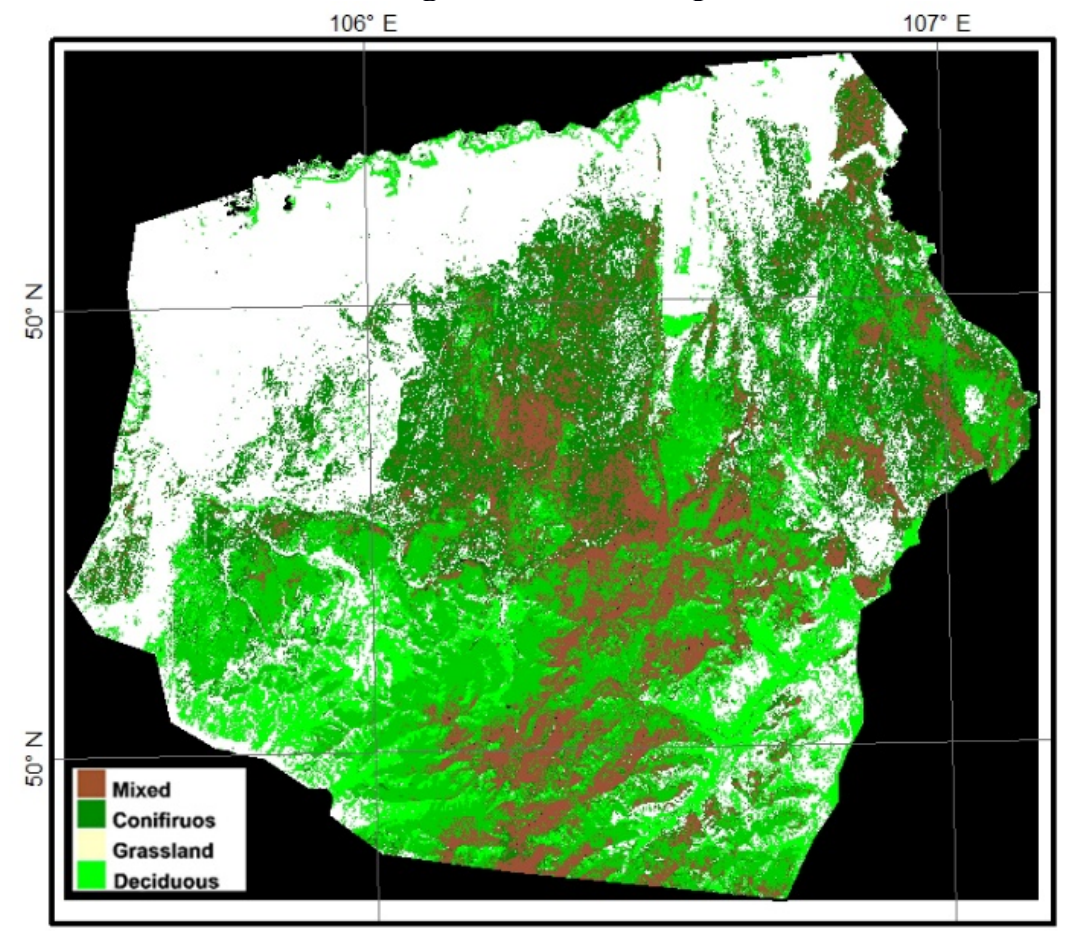

Figure 4. Vegetation map 


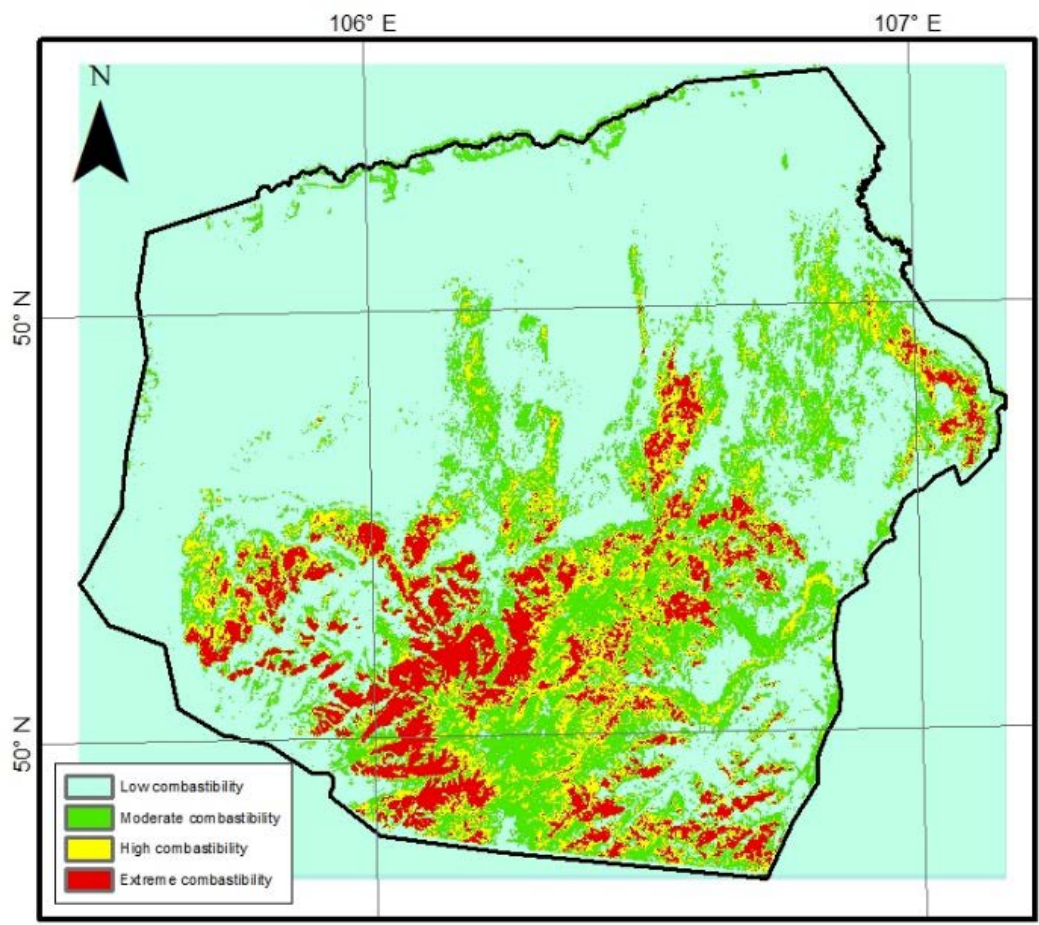

Figure 5. CI index map

\section{Topomorphology index (MI) map}

Slope map plays an important role in the topographic index. Slope modifies the relative flame inclination with respect to the ground during an upward propagation and the efficiency of heat transfers by radiation and convection; ascending fires burn more quickly on steep slopes. On the other hand, a descending slope, the speed of the fire is considerably slowed down [9]. Four slope classes were selected based on their incidence, frequency of occurrence, and spatial distribution. Figure 6 shows slope distribution map. According to the slope map, a steep slope within the forest, whereas the low slope is showed in grassland.

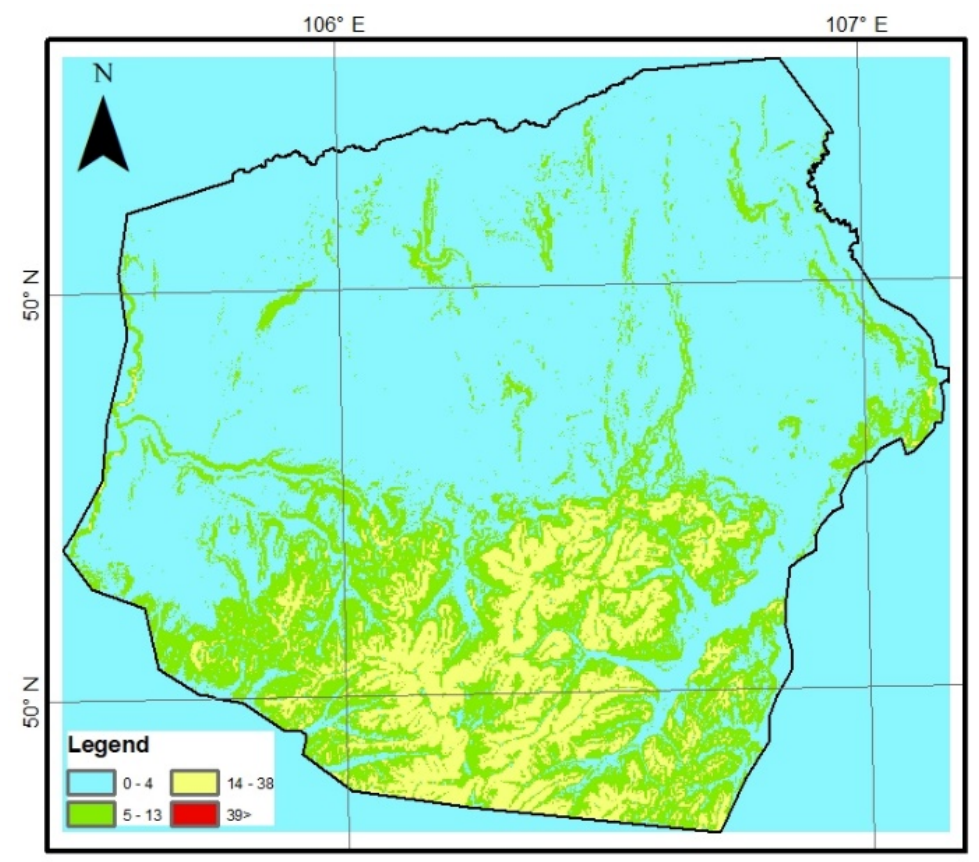

Figure 6. Slope map 


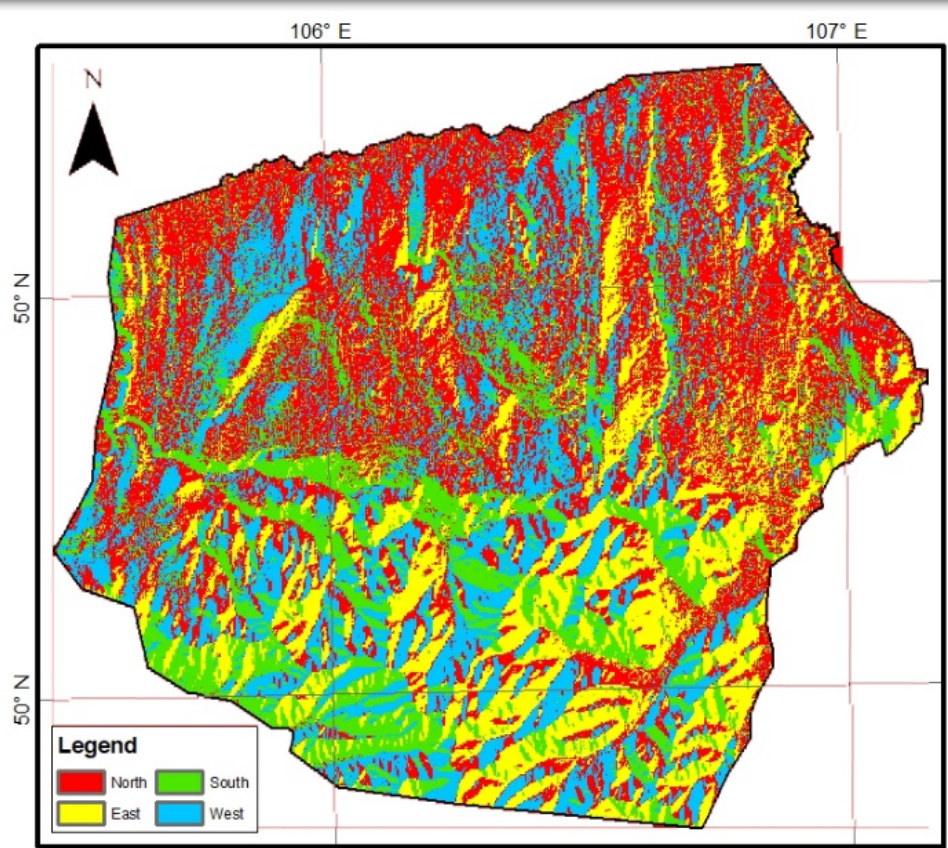

Figure 7. Aspect map

Aspect values indicate the direction the physical slopes face. Prevailing wind in Mongolia comes from the northwest which directly contributes to wildfires. In this case, northern and western slopes are most suitable conditions for wildfires. Figure 7 shows aspect map of the selected area. Four main classes of aspects were selected and northern and western aspects are coded in higher values, respectively.

The topomorphology was selected according to the classes of slopes derived from the DEM (Figure 8). Topographic variables that affect fire behaviour include elevation and aspect, which affect moisture gradients, and topographic features like narrow valleys or steep slopes, which influence fire spread. Topography also affects vegetation distribution and productivity because it impacts energy and water balances and, therefore, impacts precipitation, runoff, temperature, wind, and solar radiation [15].

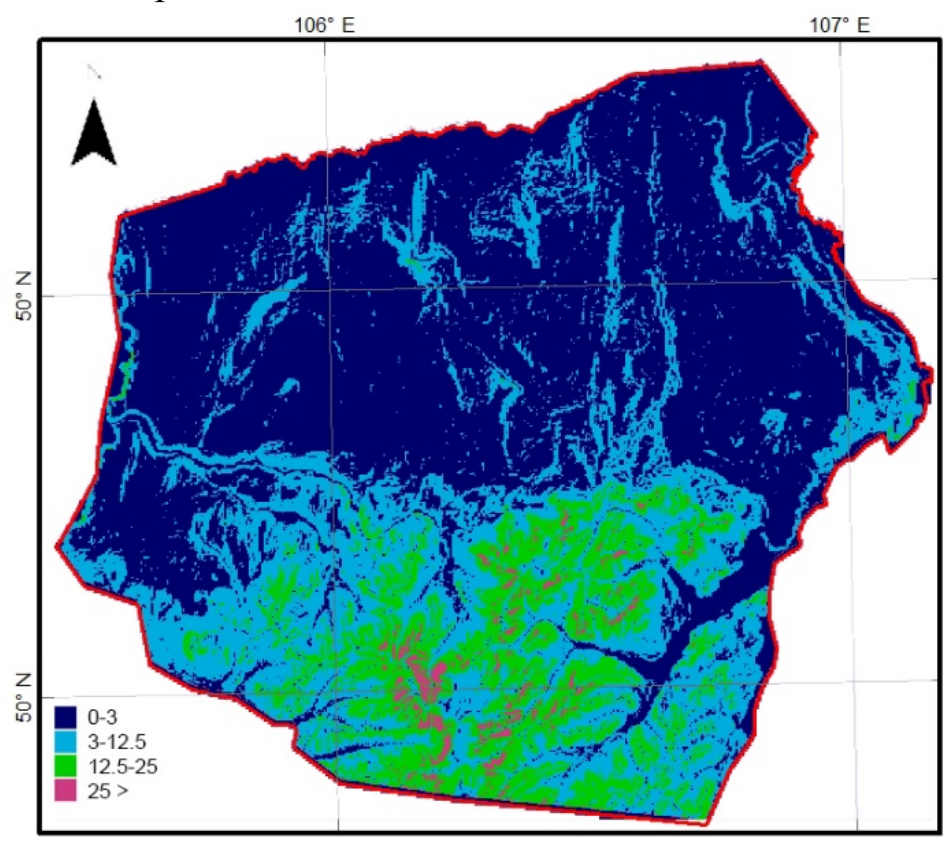

Figure 8. Topomorphological map 
Map of the Topomorphological Index (MI) is obtained from the slope, aspect and topomorphology maps (Figure 9). The results have been aggregated into four classes, each of which shows own importance (Table 1).

Table 1. Classes of the MI

MI

\begin{tabular}{ccc}
\hline MI & Importance & Code \\
\hline $0-5$ & Unfavorable & 1 \\
\hline $5-10$ & Moderate favorable & 2 \\
$10-15$ & Favorable & 3 \\
$15-25$ & Very favorable & 4 \\
\hline
\end{tabular}

\section{Human Occupation Index (HI)}

The human occupation index reflects small areas where the risk of forest fires begins; this situation is due to the low human density and the low density of the road network in the forest [9] area. The HI map is integrated into two main factors, which are the residential areas and roads. It was assimilated by a buffer of $1000 \mathrm{~m}$.

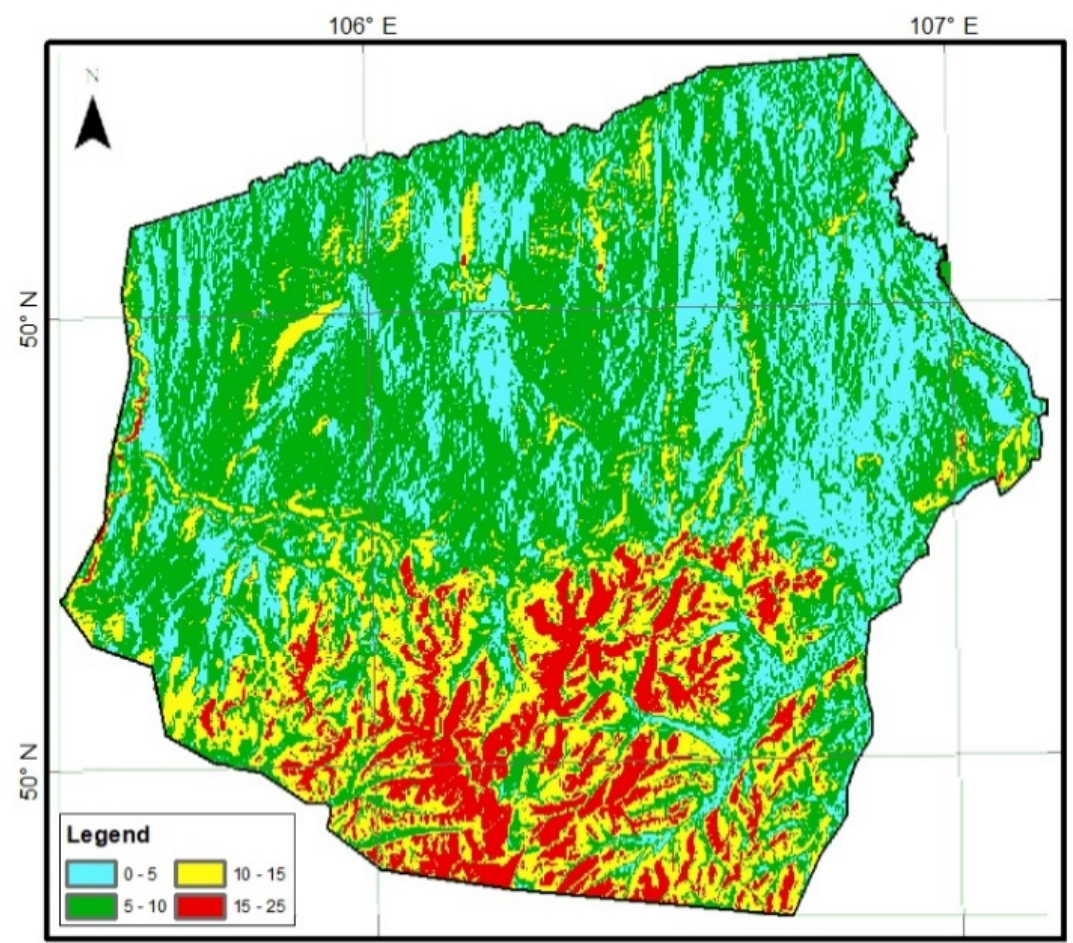

Figure 9. Map of the topomorphological index

\section{Fire Risk Index map (RI)}

The calculation of the fire risk index is the result of applying the formula (1) cited above to the integrated layers of the combustibility index, the layer of the topomorphological index, and the index of human activity. 


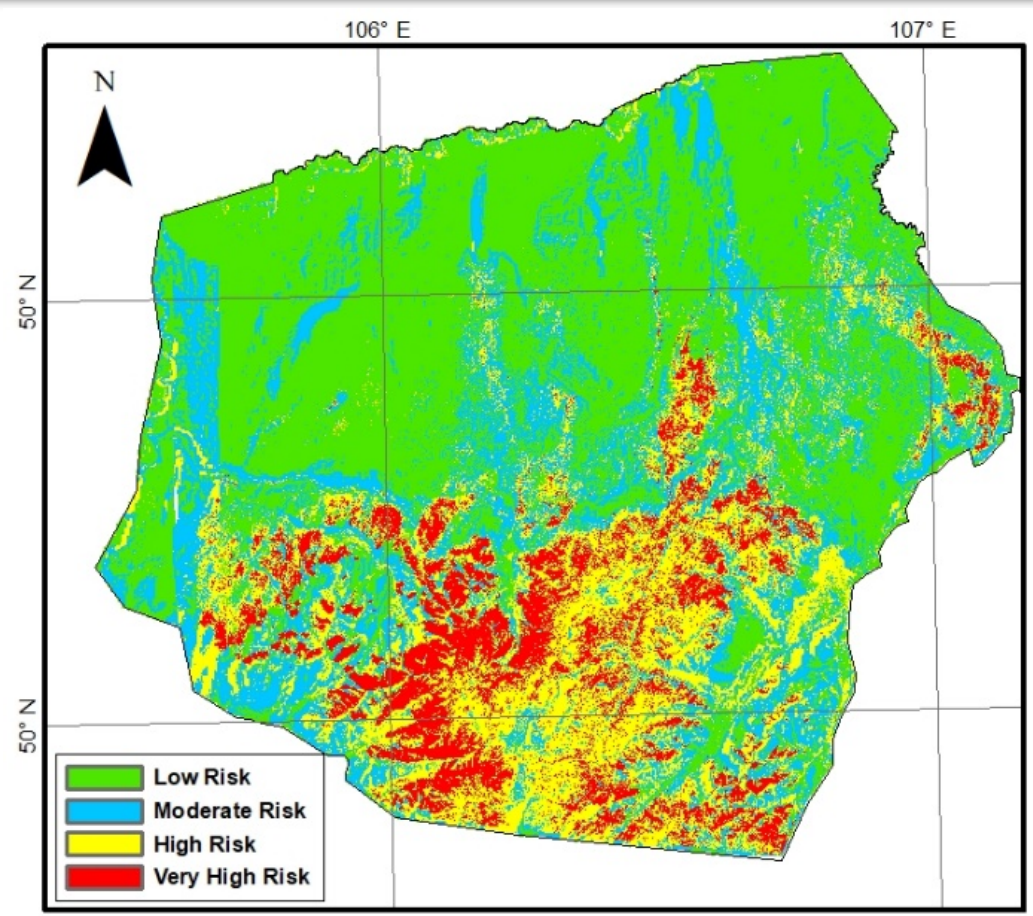

Figure 10. Map of the Fire Risk index

\section{CONCLUSIONS}

In this research, a fire-risk index map was obtained using the empirical model that integrated the parameters grouped into three sub-indexes, such as the combustibility index (CI), the topomorphology index (MI) and the human occupation index (HI). As data sources, Sentinel 2A multispectral data of May 2018 and a Sentinel 1B C-band radar data of August
2018, as well as DEM derived from Sentinel 1B data were used. Overall, the study indicated that modern GIS and RS techniques could be successfully used for generating a reliable forest fire-risk map. As seen, the outcomes of the study could be used for different forest fire prevention activities and for supporting forestrelated decision making processes.

\section{REFERENCES}

1. Haase, G. and Camphausen, A., 2007. Best Practices for Sustainable Forest Management in Southeast Asia, Deutsche Gesellschaft fur Technische Zusammenarbeit GmbH, Jakarta, Indonesia, pp. 494.

2. Amarsaikhan, D., Ganzorig, M. and Shiirev-Adya, S., 2011, Applications of advanced technology for combating land degradation and desertification in Mongolia, Proceedings of the Council Asia Conference, Ulaanbaatar, Mongolia.

3. Amarsaikhan, D., Enkhjargal, D., BatErdene, Ts., Tsogzol, G., Bolorchuluun, Ch., 2020, Classification of forest area using optical and radar images,
Proceedings of the XIII International Conference on Environment and Sustainable Development of the Mongolian Plateau and Surrounding Territories, pp.86-94

4. The Report, 2019, Report of the National Emergency Management Agency of Mongolia.

5. S. Gerelbaatar, Characteristics of forest formation of Scots pine (Pinus sylvestris L.) plantation, Dissertation, 2011, p. 115.

6. MNE (Ministry of Nature and Environment), Report on State of the Environment in 2006-2007, Ulaanbaatar, Mongolia, 2008, p. 116. 
7. Malenovský, Z., Rott, H., Cihlar, J., Schaepman, M.E., García-Santos, G., Fernandes, R.; Berger, M., Sentinels for science: Potential of Sentinel-1, -2 and -3 missions for scientific observations of ocean, cryosphere, and land.Remote Sens. Environ. 2012, 120, pp.91-101.

8. Drusch, M. Del Bello, U., Carlier, S., Colin, O., Fernandez, V., Gascon, F., Hoersch, B., Isola, C., Laberinti, P., Martimort, P., et al. Sentinel-2: ESA's Optical High-Resolution Mission for GMES Operational Services. Remote Sens. Environ. 2012, 120, pp.25-36.

9. Benguerai, A., et al. (2019). "Forest Fire Risk Assessment Model Using Remote Sensing and GIS Techniques in Northwest Algeria." Acta Silvatica et Lignaria Hungarica 15 (1): pp.9-21.

10. Zaoui, M. (2013) Fire risk management in the M'sila forest of Oran city. Master of science in forestry, ecosystem management and conservation option. Abou-bakrbelkaïd university of Tlemcen, p.177

11. Weise, D.R. Bigins, G.S. (1997): A qualitative comparison of fire spread models incorporating wind and slope effects. For. Sci. 43 (2): pp.170-180.

12. Kushla, J.D., Ripple, W.J. (1997): The role of terrain in a fire mosaic of a temperate coniferous forest. For. Ecol. Manag., 95 (2): $\quad$ pp.97-107. https://doi.org/10.1016

S03781127(97)82929-5

13. Whelan, R.J. (1995): The ecology of fire. Cambridge University Press, Cambridge

14. Anderson, H. (1982): Aids to determining fuel models for estimating fire behavior. Usda forest service, mt. bakersnoqualmie national forest, mount lake terrance, WA, USA.

15. Alexandre, P.M. et al. (2015): The relative impacts of vegetation, topography and spatial arrangement on building loss to wildfires in case studies of California and Colorado. springer science, pp.415-430. https://doi.org/10.1007/s10980-0150257-6

16. Dagorne A, Duche Y (1990) Application d'un Système d'information géographique pour l'évaluation de la vulnérabilité au feu et la prévention: Un exemple dans les Alpes-Maritimes. Bull du Comité Français de Cartographie 126:pp.16-26.

17. Tou, J. T. and R. C. Gonzalez, 1974. Pattern Recognition Principles, AddisonWesley Publishing Company, Reading, Massachusetts.

18. S.Amartuvshin, 2014, Forest cover change study using Landsat images, Research Proceedings of Mongolian University of Science and Technology, №12/159, Ulaanbaatar. Pp.34-40. 